\title{
Propriedades Psicométricas da Versão Brasileira da Escala Triangular do Amor de Sternberg
}

\author{
Psychometrics Properties of the Brazilian Version \\ of Sternberg's Triangular Love Scale \\ Vicente Cassepp-Borges" ${ }^{*}$ \& Maycoln L. M. Teodoro ${ }^{b}$ \\ aniversidade de Brasília, Brasília-DF, Brasil \\ ${ }^{\mathrm{b}}$ Universidade do Vale do Rio dos Sinos, São Leopoldo, Brasil
}

\begin{abstract}
Resumo
A Escala Triangular do Amor de Sternberg (ETAS) possui 45 itens relacionados à intimidade, paixão e decisão/compromisso. O objetivo deste estudo foi investigar algumas propriedades psicométricas da ETAS no Brasil. A versão brasileira da ETAS, o Teste da Identificação Familiar (FIT) e um questionário sobre o relacionamento foram respondidos por 361 estudantes de três universidades. A análise fatorial da ETAS apontou para uma estrutura com três fatores e elevada consistência interna. Buscando aperfeiçoar o instrumento, o número de itens da escala foi reduzido. A nova análise fatorial indicou que as propriedades psicométricas originais foram mantidas. Foram encontradas correlações positivas entre as medidas de amor e o nível de satisfação com o relacionamento. Os resultados indicam que a versão brasileira da ETAS possui propriedades psicométricas adequadas e satisfatórias.

Palavras-chave: Amor; intimidade; paixão; Psicometria; análise fatorial.

Abstract

The Sternberg's Triangular Love Scale (STLS) has 45 items related to intimacy, passion, and decision/commitment. The objective of this study was to investigate some psychometric properties of the STLS in Brazil. The Brazilian version of STLS, the Test of Family Identification (FIT) and a measure of satisfaction in the relationship were completed by 361 students from three universities. The factorial analysis of STLS showed a structure with 3 factors and elevated internal consistency. Seeking to improve the instrument, the number of items of the scale was reduced. The new factorial analysis indicated that the original psychometric properties were maintained. Positive correlations were found between the measurements of love and the level of satisfaction with the relationship. The results indicate that the Brazilian version of ETAS possesses adequate and satisfactory psychometric properties

Keywords: Love; intimacy; passion; Psychometrics; factor analysis.
\end{abstract}

Cada indivíduo cria, escreve e vive inúmeras histórias de amor durante a sua vida. O curso e a intensidade destas experiências são de fundamental importância para a realização e o desenvolvimento pessoal. Deste modo, a vivência do amor é buscada por muitos devido à sua relevância para as relações interpessoais e também por se tratar de um dos sentimentos mais fortes e prazerosos da vida (Sternberg, 1998; Sternberg \& Grajek, 1984).

Apesar de ser um campo historicamente pertencente à especulação de artistas e filósofos, o amor cada vez mais vem sendo explorado pela ciência (Aron \& Westbay, 1996; Engel, Olson, \& Patrick, 2002; Reis, 1992). Platão (citado por Schoepflin, 2004) descreveu o amor (Eros) como o sentimento que faz superar as baixezas do mundo material para elevar ao mundo das idéias. Freud (1915/1969) complementou a idéia de Platão, afirmando que o amor

\footnotetext{
Endereço para correspondência: Universidade de Brasília, Campus Darcy Ribeiro, ICC Sul, Instituto de Psicologia, LABPAM, Sala A1-096 - CEP 90910-900 , Brasília-DF Email: cassepp@gmail.com
}

está associado aos instintos sexuais e que somente se torna o oposto do ódio depois de estabelecida a organização genital. Skinner (1991) salientou que o amor é um reforçamento mútuo de comportamentos, idéia confirmada posteriormente por estudos com neuroimagem, os quais sugerem que o sistema de recompensa é aquele que mais é ativado quando se mostra a foto de uma pessoa amada (Aron, Fisher, Mashek, Strong, Li, \& Brown, 2005).

Um dos primeiros esforços para mensurar o amor descrito na literatura foi feito apenas no final da década de 60 por Zick Rubin (1970), por meio de uma diferenciação dos sentimentos de amar e gostar. Segundo ele, amar se refere à atração física, predisposição para ajudar, desejar compartilhar emoções e experiências e ao sentimento de exclusividade e absorção. Gostar está relacionado com as relações interpessoais e inclui sentimentos como o respeito, a confiança e a percepção de que a pessoa amada tem objetivos semelhantes aos seus próprios. Assim, o autor desenvolveu uma escala de amar e outra de gostar, as quais aplicou em 158 casais da Universidade de Michigan. Ambas as escalas mostraram ter consistência interna satisfatória 
( $\alpha=, 84$ para homens e $\alpha=, 82$ para mulheres na escala de amor e $\alpha=, 83$ para homens e $\alpha=, 81$ para mulheres na escala de gostar). Os sentimentos de gostar e amar apresentaram uma maior correlação na amostra masculina $(r=, 60)$ do que na feminina $(r=, 39)$, havendo significância nesta diferença $(z=2.48, p<0,05)$. Estes dados sugerem que as mulheres possuem uma capacidade mais acurada de diferenciar os dois sentimentos. Os casais com escores elevados na escala de amor tendem a permanecer mais tempo nas trocas de olhares do que os casais com escores mais baixos, indicando uma boa validade externa deste instrumento.

Sternberg $(1986,1988)$ apresentou a Teoria Triangular do Amor, construída através da decomposição deste sentimento em três elementos (vértices de um triângulo): a intimidade, a paixão e a decisão/compromisso. A intimidade é caracterizada pelo sentimento de proximidade e conexão no relacionamento. A paixão é o componente responsável pela atração física e sexual, pelo romance e o desejo de estar juntos e pela excitação. Por fim, a decisão/ compromisso refere-se à certeza de amar e ser amado e à vontade de manter o relacionamento em longo prazo. Martson, Hecht, Manke, McDaniel e Reeder (1998), através da análise fatorial de um questionário aberto, sugeriram que a intimidade é composta por abertura, sexo, afetividade, capacidade de apoiar e companhia silenciosa. A experiência da paixão é composta pelo romantismo e pela intimidade sexual. Por fim, a experiência do compromisso se trata da capacidade de dar suporte, expressões do amor, fidelidade, expressões do compromisso e consideração e devoção.

A composição dos vértices do triângulo origina sete diferentes formas de amar (Figura 1). A ausência dos três vértices representa a ausência de amor. O componente intimidade isolado ocasiona o "gostar", ou seja, um sentimento próximo à amizade. $\mathrm{O}$ componente paixão traz um elevado grau de excitação, que tende a ser momentânea caso não seja acompanhada dos demais componentes. $\mathrm{O}$ componente decisão/compromisso faz com que um casal fique unido pela aceitação de forças externas, como o medo da reação do parceiro em caso de fim do relacionamento ou a concordância com casamentos arranjados, sendo este chamado de amor vazio (Sternberg, 1986, 1988).

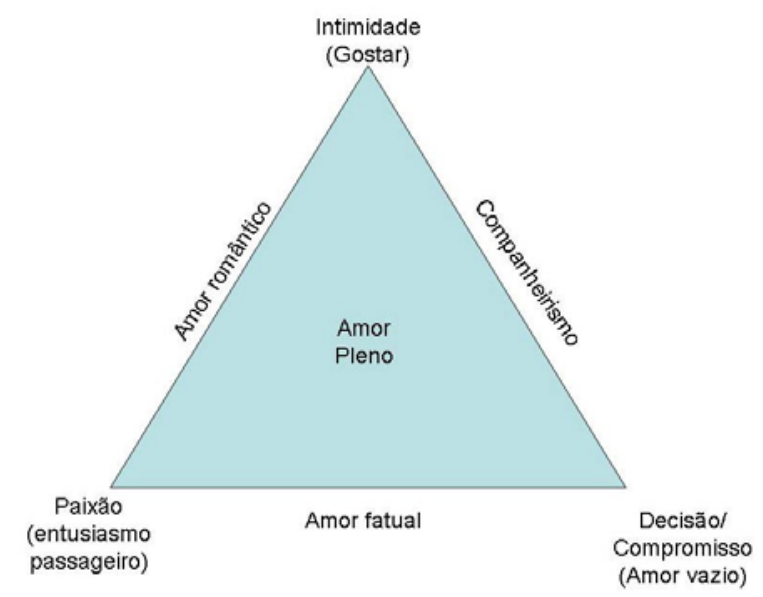

Figura 1. O triângulo do amor de Sternberg (1986).
Os tipos de amor compostos por pelo menos dois vértices obviamente representam formas mais intensas de amar. A intimidade e a paixão juntas produzem o amor romântico. Este é um tipo de amor bastante descrito na ficção. Romeu e Julieta, por exemplo, possuíam uma ligação bastante forte, sem, porém, poder estabelecer um compromisso. A combinação entre as dimensões da intimidade e decisão/compromisso forma o companheirismo, comum entre casais que permanecem unidos e felizes mesmo depois que a atração física termina. $\mathrm{O}$ amor fatual pode ser associado ao amor à primeira vista, quando se verificam as dimensões da paixão e da decisão/compromisso de maneira marcada, mas sem que se tenha tido tempo de estabelecer qualquer vínculo de intimidade. Por fim, Sternberg $(1986,1988)$ descreveu o amor pleno, composto pelos três vértices do triângulo.

No intuito de fornecer suporte empírico à Teoria Triangular do Amor, foi desenvolvida uma escala que abrange os componentes teóricos intimidade, paixão e decisão/ compromisso. A validação de construto da Escala Triangular do Amor de Sternberg (ETAS) foi feita nos Estados Unidos com a participação de 84 adultos. Os participantes responderam à primeira versão da ETAS e às escalas de amar e gostar de Rubin (1970), utilizadas para a validação externa da ETAS. Cada escala foi respondida seis vezes, descrevendo-se o amor que sente pela mãe, pelo pai, por um(a) irmã(o), por um(a) amigo(a) do mesmo sexo, pela pessoa que ama e por um(a) amante ideal. A quantificação da importância do amor foi feita por outro grupo de participantes para os seis relacionamentos anteriormente descritos. Os resultados mostraram que o efeito da variável gênero não foi estatisticamente significativo. Apesar disso, as mulheres obtiveram índices mais altos para a melhor amiga e o amante ideal. As médias referentes à pessoa amada e ao(à) amante ideal foram muito maiores que as demais, principalmente no componente da paixão (Sternberg, 1997).

Com relação à análise interna da ETAS, as análises mostraram coeficientes alphas superiores a 0,80, com exceção de uma na dimensão da decisão/compromisso $(a=0,79)$. Apesar disso, um dos grandes problemas da escala foi a elevada correlação entre a intimidade, a paixão e a decisão/compromisso. Pode-se creditar estas correlações ao fato da escala ter sido aplicada em casais, dos quais se espera que possuam vários componentes do triângulo em seus relacionamentos (Sternberg, 1997). Isto prejudica a análise fatorial da mesma. Nem todos os itens saturaram de maneira mais forte no fator para o qual era esperado que isto ocorresse, o que faz a escala parecer baseada em apenas um construto, e não em três.

Em um segundo estudo, publicado no mesmo artigo, Sternberg (1997) substituiu os itens que considerou problemáticos e acrescentou três itens em cada subescala, culminando num total de 45 itens. Todos os coeficientes alphas foram superiores a 0,90, ampliando a consistência interna da escala. Porém, as correlações entre as três subescalas foram entre 0,71 e 0,73. Apesar de estes níveis terem sido mais baixos do que os encontrados no estudo 
1, não se pode afirmar que foi resolvido o problema da unicidade das subescalas.

Outras aplicações da escala, em diversas partes do mundo, também encontraram os mesmos problemas apontados por Sternberg (1997). A análise fatorial de Hendrick e Hendrick (1989) com a versão original (apesar de ele ter utilizado uma escala Likert de 5 pontos) também se mostrou problemática, com vários itens saturando em mais de um fator. Chojnacki e Walsh (1990) encontraram uma elevada concordância na reaplicação da ETAS após duas semanas, mas citaram a correlação entre os fatores como o ponto fraco da escala. Yela (1996), com uma amostra de 412 sujeitos, não encontrou total apoio empírico à estrutura fatorial da ETAS. Assim, uma solução apontada na literatura é a redução de itens. Com uma escala semelhante à proposta por Sternberg, porém com somente 20 itens, Lemieux e Hale (2000) obtiveram um instrumento que praticamente eliminou a sobreposição de itens em fatores não pretendidos. Assim, os autores sugerem que a ETAS deve ser um instrumento mais curto e mais preciso.

No Brasil, uma versão desta escala foi aplicada em 98 alunos de pós-graduação de ambos os sexos (Hernandez, 1999). A exemplo da aplicação original (Sternberg, 1997), os valores dos coeficientes alphas obtidos no Brasil também foram elevados, sendo superiores a $0,90 \mathrm{em}$ todas as subescalas. O alpha total foi de 0,97. A escala, porém, também encontrou problemas em sua análise fatorial. Em uma solução com três fatores em rotação varimax, 12 dos 45 itens $(26,7 \%)$ totais saturaram mais fortemente em um fator diferente do pretendido. Apesar disso, o maior problema da escala foi constatado em quatro itens pretendidos para o construto "paixão", que saturaram fortemente no fator "compromisso" e discretamente (abaixo de 0,21) no fator "paixão". Os resultados do estudo de Hernandez em desacordo com a teoria podem ser reflexo do baixo número de participantes no estudo (veja Bortz, 2005), o que dificultaria a interpretação sobre o uso da escala no Brasil.

Tendo em vista a possível utilização da ETAS em pesquisas sobre o amor realizadas no Brasil, este estudo pretende, em caráter exploratório, avaliar algumas propriedades psicométricas desta escala em uma amostra universitária do Rio Grande do Sul. Além disso, pretende-se ainda investigar as imprecisões da ETAS descritas na literatura (Chojnacki \& Walsh, 1990; Hendrick \& Hendrick, 1989; Hernandez, 1999; Sternberg, 1997; Yela, 1996), a fim de se aperfeiçoar a escala.

\section{Método}

\section{Participantes}

Os participantes foram 361 estudantes universitários de ambos os sexos, sendo 131 homens (36,3\%) e 230 mulheres $(63,7 \%)$. A idade média dos participantes foi de 25,25 anos $(D P=6,08)$ para o grupo masculino e de 24,75 anos $(D P=6,01)$ para o feminino. A amostra é oriunda de três universidades da Grande Porto Alegre e do Vale dos Sinos (RS). Os estudantes cursavam 23 cursos diferentes, de diversas áreas do conhecimento. Os participantes foram $122(33,7 \%)$ estudantes da área da saúde (Cursos de
Psicologia e Biomedicina), 122 (33,7\%) da área econômica (Administração de Empresas, Recursos Humanos, Comércio Exterior, Ciências Contábeis, dentre outros), 80 (22,1\%) da área das ciências exatas (Arquitetura e Urbanismo, diversas Informáticas e diversas Engenharias) e 38 (10,5\%) da área das ciências humanas e da comunicação (História, Relações Públicas, Jornalismo, Direito, dentre outros).

Diferentemente da maioria dos estudos anteriores, também participaram da amostra pessoas que não possuem parceiro(a). Quanto à opção sexual, 5 participantes $(1,4 \%)$ se declararam homossexuais e $4(1,1 \%)$ bissexuais, sendo os restantes heterossexuais. Os participantes escolheram uma pessoa que amam para responder à pesquisa. $\mathrm{O}$ tipo de relacionamento de cada participante foi categorizado. Analisando-se apenas os casos em que era percebido um relacionamento (namoro, casamento, noivado e união estável, $n=238,65,9 \%$ ), os homens escolheram uma pessoa em média 1,12 anos mais nova $(D P=3,48)$. Já as mulheres escolheram pessoas 2,72 anos mais velhas $(D P=4,41)$, sendo esta diferença significativa $(t=6,685, g l=233, p<$ o,001) e já encontrada em outros estudos (Buss, 1989).

\section{Instrumentos}

Foi utilizada uma versão em português da ETAS. Esta versão foi obtida através do procedimento de dupla back translation da escala original e validação de conteúdo, no qual duas pessoas traduziram o instrumento do inglês para o português e outras duas re-traduziram a escala para o inglês às cegas. Para a validação de conteúdo, a escala foi analisada aos três juízes-avaliadores, conhecedores da Teoria Triangular do Amor. Eles pontuaram, em uma escala Likert de 5 pontos, o quanto cada item possuía clareza de linguagem, pertinência prática e relevância teórica. A análise dos dados foi feita através do cálculo do Coeficiente de Validade de Conteúdo (CVC), cuja fórmula considera o número de juízes e a média das respostas deles (HernándezNieto, 2002). Tendo em vista que a versão traduzida da ETAS não obteve um CVC satisfatório com relação à clareza de linguagem para todos os itens, procedeu-se a uma reformulação das 20 frases problemáticas. Os itens modificados foram novamente submetidos para os mesmos juízes, que refizeram a avaliação. A versão final do questionário apresentou concordância na tradução e índices de validade de conteúdo satisfatórios $(\mathrm{CVC}>0,80)$ para aplicação em universitários brasileiros. Os juízes atribuíram uma dimensão para cada item, e o nível de concordância entre a dimensão atribuída por eles e a dimensão originalmente proposta $\left(k a p p a_{\text {médio }}=0,750\right)$ foi considerado aceitável (Landis \& Koch, 1977).

Foi incluído um questionário sócio-demográfico com itens quantitativos e qualitativos com respeito à descrição da pessoa amada e do tipo de relação vivida. Este questionário foi formulado com base nos estudos anteriores sobre o amor (Chojnacki \& Walsh, 1990; Hendrick \& Hendrick, 1989; Reis, 1992, 1995; Serrano Martinez \& Carreño Fernandez, 1993; Sternberg, 1986, 1988, 1997; Sternberg \& Grajek, 1984; Yela, 1996) e continha perguntas com relação a sexo, idade, estado civil, idade e sexo do(a) parceiro(a), grau de satisfação com o relacionamen- 
to (avaliado de acordo com uma escala Likert variando de 1 a 9) e descrições sobre esta relação.

Como indicador da validade externa, foi utilizado o Teste de Identificação Familiar (FIT). Este teste foi desenvolvido por Remschmidt e Mattejat (1999) a partir de outros processos psicodiagnósticos, tais como a Grade de Kelly (1955) e o Procedimento de Classificação de Cartões $Q$ Sort (Stephenson, 1953). Estudos iniciais com o FIT no Brasil mostraram sua aplicabilidade para o contexto brasileiro (Teodoro, 2000) e sua capacidade de explicar parte da variância da qualidade de vida de crianças (Teodoro, 2005). O objetivo do FIT é pesquisar as relações de identificação na família. Os atributos de personalidade com que ele trabalha foram escolhidos em função das dimensões mais comumente aceitas para caracterizar a personalidade, tais como: extroversão/introversão ou estabilidade/ labilidade emocional (Eysenck, 1970).

O FIT consiste em 12 adjetivos (atributos de personalidade), com os quais o participante deverá descrever por meio de uma escala Likert de cinco pontos como ele é (self real), como ele gostaria de ser (self ideal), como o parceiro é (parceiro real) e como ele gostaria que o parceiro fosse (parceiro ideal). Posteriormente, os dados deste instrumento foram correlacionados para cada participante nestes quatro aspectos levantados. Para este estudo, foram analisadas as variáveis identificação real com o parceiro (correlação entre self real e parceiro real; i.e, Eu sou como o meu parceiro), identificação ideal com o parceiro (correlação entre self ideal e parceiro real; i.e., Eu gostaria de ser como o meu parceiro) e semelhança parceiro-parceiro ideal (correlação parceiro real e parceiro ideal; i.e., Meu parceiro é do jeito que eu gostaria que ele fosse). Espera-se uma correlação positiva entre os escores de identificação real e ideal com o parceiro e semelhança entre parceiro real e ideal do FIT com os escores de amor na ETAS. Análises semelhantes foram feitas no estudo de Serrano Martinez, e Carreño Fernandez (1993). A amostra do estudo em questão respondeu à ETAS em "Como me sinto", "Como gostaria de me sentir", "Como acredito que meu(minha) parceiro(a) se sente" e "Como gostaria que meu(minha) parceiro(a) se sentisse". Os resultados indicaram que os sujeitos deste estudo gostariam de possuir mais Paixão, Intimidade e Decisão/compromisso nas suas relações.

\section{Procedimentos}

A aplicação foi feita de maneira coletiva. Além dos instrumentos, os participantes preencheram duas vias de um termo de consentimento livre e esclarecido. Aqueles participantes que preencheram um campo do termo de consentimento com o endereço de correio eletrônico receberam uma devolução individualizada com os principais resultados da pesquisa. Este projeto foi aprovado pelo Comitê de Ética em Pesquisa da Universidade do Vale do Rio dos Sinos (Processo 052/2005).

\section{Análise dos Dados}

As descrições do FIT foram correlacionadas entre si, formando escores de identificação real com o parceiro (self real e parceiro real), identificação ideal com o parceiro (self ideal e parceiro) e semelhança parceiro-parceiro ideal. Todos os escores de correlação do FIT foram transformados em escores Z-Fisher para possibilitar a sua comparação com a ETAS. Finalmente, a ETAS foi analisada por meio de análise fatorial exploratória com o método de extração dos componentes principais e rotação promax. Esta rotação foi escolhida por ser oblíqua, não omitindo a possibilidade de correlação entre os fatores (Chojnacki, \& Walsh, 1990; Hendrick \& Hendrick, 1989; Hernandez, 1999; Lemieux \& Hale, 1999, 2000; Sternberg, 1997; Yela, 1996). O número de sujeitos da amostra também motivou esta escolha. Foram calculados os coeficientes alphas de Cronbach e as correlações entre as subescalas.

\section{Resultados}

Os resultados foram divididos em duas partes. A primeira apresenta a análise dos resultados da versão adaptada da ETAS com seus 45 itens. Esta versão é aquela que vem sendo mais utilizada internacionalmente (Masuda, 2003). Na segunda parte, é feita uma re-análise dos dados e apresentada uma versão reduzida da escala, com apenas 18 itens. Esta análise foi realizada porque a redução de itens obteve bons resultados em estudos recentes (Lemieux \& Hale, 1999, 2000).

\section{Análise Fatorial da ETAS}

Inicialmente, foi realizada uma análise fatorial exploratória com o método dos componentes principais e rotação promax com os itens traduzidos da ETAS. O resultado do teste de esfericidade de Bartlett foi significativo $\left(\chi^{2}\right.$ aprox. $=13789,555 ; g l=990 ; p<0,001)$ e o valor da adequacidade amostral dos itens, medida pelo teste KaiserMeyer-Olkin, foi de 0,96, indicando que a covariância da matriz é bastante acentuada e justificando que a análise é apropriada.

Caso a análise fosse feita considerando-se um valor de eigenvalue superior a 1 (método de Kaiser), seria retida uma solução com 6 fatores. Porém, sabe-se que este método tende a elevar o número de fatores quando o número de itens também é elevado (Reise, Waller, \& Comrey, 2000; Zwick \& Velicer, 1986). Assim o Scree Plot (Figura 2) foi o critério utilizado para determinar o número de fatores. Foram encontrados os três fatores previstos pela Teoria Triangular do Amor (Sternberg, 1986, 1988). Como pode ser visto na Tabela 1, os três fatores apresentados de fato correspondem a Intimidade, Decisão/Compromisso e Paixão. Apenas sete itens $(17,78 \%)$ saturaram de maneira mais forte em um fator no qual não era esperado. Esta solução explicou $63,41 \%$ da variância total da escala, dividida entre o fator Intimidade $(43,10 \%)$, o fator Decisão/compromisso $(44,06 \%)$ e o fator Paixão $(32,08 \%)^{1}$.

${ }^{1}$ A soma variância explicada por cada uma das três dimensões é maior do que o valor da variância total porque os fatores são correlacionados. 
Cassepp-Borges, V. \& Teodoro, M. (2007). Propriedades Psicométricas da Versão Brasileira da Escala Triangular do Amor de Sternberg.

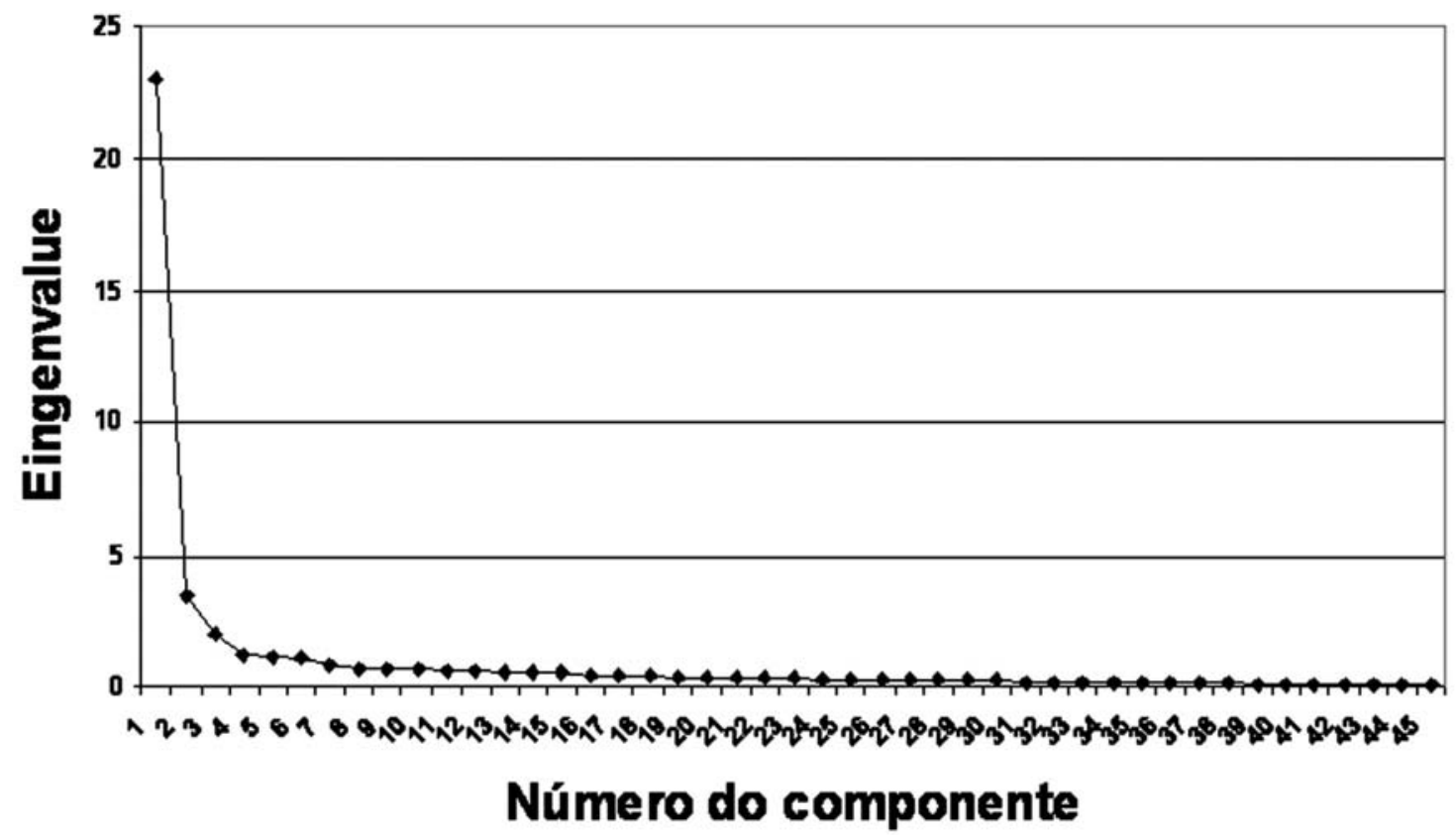

Figura 2. Scree Plot da Análise Fatorial da Escala Triangular do Amor de Sternberg (ETAS).

Tabela 1

Análise Fatorial Exploratória da Escala Triangular do Amor de Sternberg (ETAS) com o Método dos Componentes Principais e Rotação Promax

\begin{tabular}{|c|c|c|c|}
\hline \multirow{2}{*}{ Item } & \multicolumn{3}{|c|}{ Fator } \\
\hline & Intimidade & $\begin{array}{l}\text { Decisão } \\
\text { Compromisso }\end{array}$ & Paixão \\
\hline 17 (I) - Eu me comunico bem com & 1,034 &,- 365 & \\
\hline 11 (I) - Eu sinto que ___ realmente me entende. & 861 & & \\
\hline 14 (I) - Eu recebo muito apoio emocional de &, 771 & & \\
\hline 10 (I) - Eu ativamente promovo o bem estar de &, 753 & & \\
\hline 21 (I) - Tenho uma relação afetuosa com &, 738 & & \\
\hline 34 (I) - Tenho uma relação agradável com _ـ. &, 733 & & \\
\hline 41 (I) - Eu posso contar com ___ quando tiver necessidade. &, 707 & & \\
\hline 36 (I) - Eu sinto que eu realmente entendo &, 701 & & \\
\hline 39 (I) - Eu dou muito apoio emocional a & ,699 & & \\
\hline 24 (I) - ___ pode contar comigo quando tiver necessidade. & 657 & & \\
\hline o3 (I) - Eu sinto que realmente posso confiar em & 644 & & \\
\hline 44 (I) - Eu me sinto próximo de & ,633 &, 365 & \\
\hline $\mathrm{O} 9(\mathrm{P})-\mathrm{Eu}$ adoro & ,605 & & ,346 \\
\hline o6 (I) - Eu divido intensamente meus assuntos pessoais com &, 556 & & \\
\hline $35(\mathrm{D} / \mathrm{C})$ - Eu sei que me importo com &, 507 & & \\
\hline O4 (I) - Eu valorizo muito ___ na minha vida. & 434 &, 420 & \\
\hline 28 (D/C) - Vejo como boa a decisão de me relacionar com &, 335 & & ,308 \\
\hline O 1 (P) - Não posso imaginar minha vida sem & & ,942 & \\
\hline $23(\mathrm{D} / \mathrm{C})$ - ___ pode contar comigo quando tiver necessidade. & &, 888 & \\
\hline 32 (D/C) - Não deixaria nada atrapalhar meu compromisso com & & ,830 & \\
\hline $22(\mathrm{D} / \mathrm{C})$ - Espero que meu amor por ___ dure pelo resto da vida. & &, 785 & \\
\hline 19 (D/C) - Tenho um compromisso com __ portanto não permitirei & & & \\
\hline que outras pessoas se ponham entre nós. & &, 751 & \\
\hline
\end{tabular}




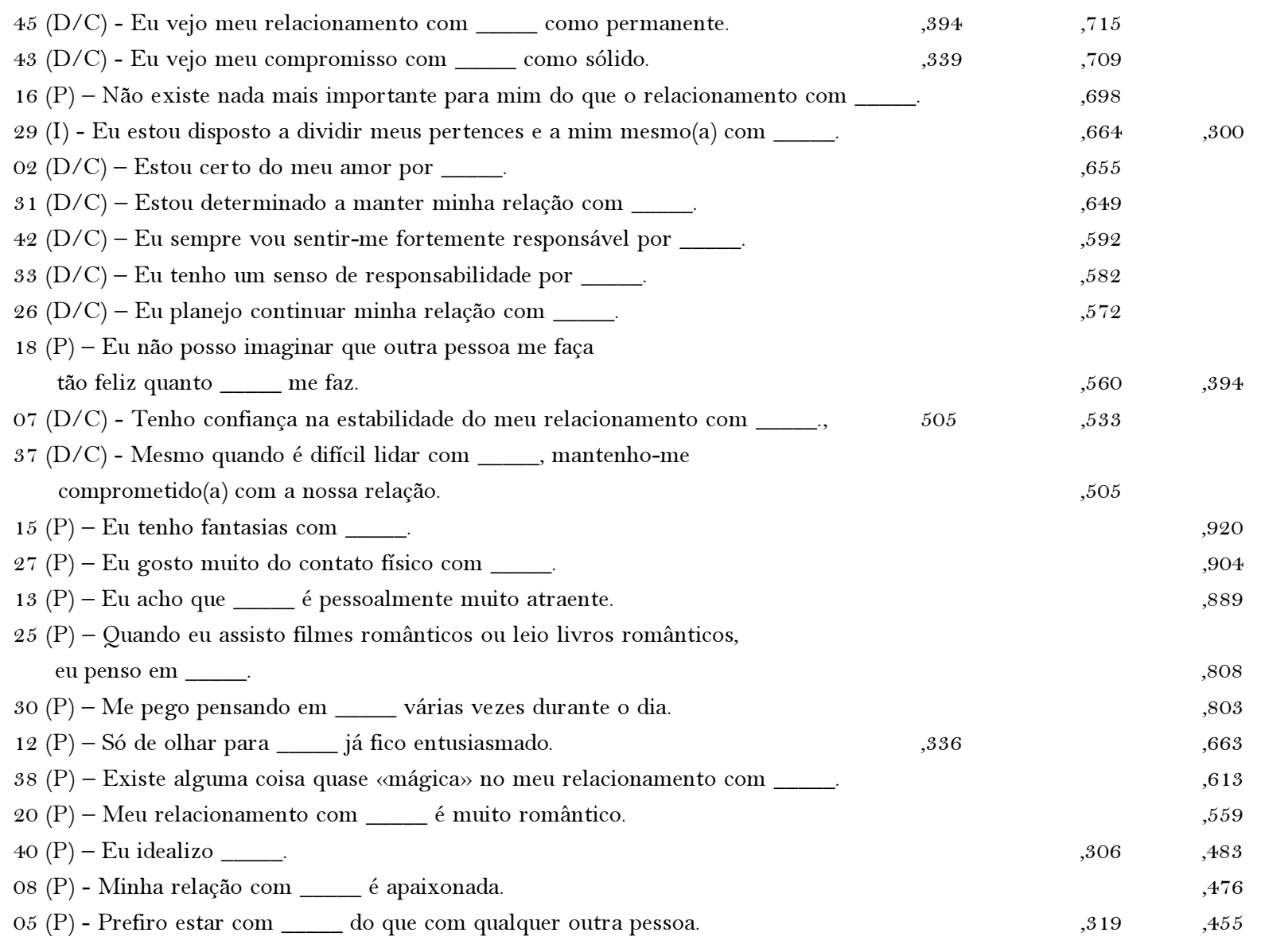

Notas. As letras entre parênteses representam a dimensão original do item, conforme proposto por Sternberg (1988, 1997). I - Intimidade, P- Paixão e D/C-Decisão/Compromisso.

As cargas fatorias provenientes de uma análise fatorial com rotação promax devem se interpretadas como escores de regressão. Por este motivo, valores acima de um são possíveis.

Posteriormente, foram feitas as análises de confiabilidade da escala e das subescalas. Em um primeiro momento, foi desconsiderada a solução fatorial apresentada anteriormente, calculando-se os valores de alpha de Cronbach propostos da escala original (Sternberg, 1988, 1997). Assim, a escala apresentou elevada consistência interna na três subescalas, de 15 itens cada $\left(\alpha_{\text {intimidade }}=0,943 ; \alpha_{\text {paixão }}=0,932\right.$; $\left.\alpha_{\text {decisão/compromisso }}=0,960\right)$. A consistência interna é um pouco maior quando os itens de cada subescala são distribuídos de acordo com o resultado da análise fatorial $\left(\alpha_{\text {intimidade }}=\right.$ $0,954,18$ itens; $\alpha_{\text {paixão }}=0,927,11$ itens; $\alpha_{\text {decisäo/compromisso }}=$ 0,964, 18 itens). Os itens 04 e 07 pertencem a dois fatores (intimidade e Decisão/Compromisso) simultaneamente. Apesar de a teoria prever uma independência entre os fatores, a elevada correlação entre eles permite que sejam feitas análises para o amor como um todo. Assim, o valor total de Alpha para os 45 itens da escala foi de 0,977 , mostrando que a ETAS possui uma consistência interna satisfatória.
O FIT foi utilizado como primeiro critério de validade convergente. Foram analisados apenas os(as) participantes que namoravam, eram casados, noivos ou em união estável $(n=239,66,0 \%)$ para selecionar apenas aqueles que estavam vivenciando uma relação amorosa com um parceiro. As correlações entre as dimensões utilizadas do FIT (identificação real com o parceiro, identificação ideal com o parceiro e semelhança parceiro-parceiro ideal) com as dimensões da ETAS encontram-se na Tabela 2. As identificações e congruências foram correlacionadas com o total da ETAS e com os três fatores do amor, extraídos da análise fatorial (vide Tabela 1). Apesar de positivas e significativas, as correlações foram moderadas. Conforme esperado, a dimensão da intimidade foi aquela que obteve escores mais elevados. 
Tabela 2

Índices de Correlação de Pearson entre as Identificações Real e ideal e Semelhança do Teste de Identificação Familiar (FIT) com as versões completa e reduzida Escala Triangular do Amor de Sternberg (ETAS)

\begin{tabular}{|c|c|c|c|c|c|}
\hline \multirow{2}{*}{ Identificação e semelhança (FIT) } & & \multicolumn{4}{|c|}{ Dimensões do amor (ETAS) } \\
\hline & & Intimidade & Paixão & Decisão/compr. & Amor total \\
\hline \multirow[t]{2}{*}{ Identificação real com a pessoa amada } & Versão completa & ,269****** &, $232 * *$ &, $154 *$ &, $195 * *$ \\
\hline & Versão reduzida & ,233米米 & ,206米 &, 103 &, 197 *⿻丷木 \\
\hline \multirow[t]{2}{*}{ Identificação ideal com a pessoa amada } & Versão completa &, $395^{*}$ *⿻丷木米 & ,363米米 &, 212 *** & ,359米米 \\
\hline & Versão reduzida &, 371 米米 & 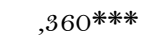 &, $244^{*} * * * 6$ & ,359****** \\
\hline \multirow[t]{2}{*}{ Semelhança do parceiro real com o parceiro ideal } & Versão completa & ,433米米 & ,346 米米 &, $179^{* *}$ &, 355 米米 \\
\hline & Versão reduzida &, 417 米米 & ,340米米米 & ,196**⿻丷木 & ,347 米米米 \\
\hline
\end{tabular}

Nota. ${ }^{*} p<0,05 ;$ *** $p<0,01 ; * * * p<0,001$.

O segundo critério de validade convergente foi a correlação da ETAS com a percepção subjetiva da satisfação com o relacionamento. Esta satisfação foi medida através de uma escala Likert de 1 a 9, a qual foi preenchida juntamente com o questionário que antecedia a pesquisa. Mais uma vez, foram utilizados os escores $Z$ oriundos da análise fatorial descrita na Tabela 1. A Tabela 3 mostra a correlação entre os fatores da ETAS e a satisfação com o relacionamento.

Tabela 3

Índices de Correlação de Pearson entre a Escala Triangular do Amor de Sternberg (ETAS) e o Nível de Satisfação no Relacionamento

\begin{tabular}{lccccc} 
& Intimidade & Paixão & Decisão/compr. & Amor total & Satisfação \\
\hline Intimidade & - &, $539^{* * * *}$ &, $739^{* * * *}$ &, $891^{* * * *}$ &, $735^{* * * *}$ \\
Paixão & & - &, $575^{* * * *}$ &, $764^{* * * *}$ &, $344^{* * * *}$ \\
Decisão/compr. & & - &, $923^{* * * *}$ &, $664^{* * * *}$ \\
Amor total & & - & - &, $711^{* * * *}$ \\
\hline
\end{tabular}

Nota. $* * * * 0,001$.

Através da Tabela 3, pode-se perceber que existem correlações elevadas entre a ETAS e a percepção da satisfação com o relacionamento. A exceção está na correlação com a dimensão da paixão $(r=0,344 ; p<0,001)$. Uma possibilidade para a ocorrência deste fato é a de que a dimensão da paixão está associada com a atração sexual, e houve participantes que responderam à escala mencionando o amor por parentes, (pais, filhos, irmãos, etc.). Analisando-se apenas os sujeitos envolvidos em um relacionamento (mesmo critério utilizado para a Tabela 2 ), o valor desta correlação sobe para $0,630(p<0,001)$. Já a correlação entre satisfação e paixão para o grupo de participantes que responderam à ETAS pensando em um parente foi negativa e não significativa $(r=-0,110, p=\mathrm{n}$. s.). É importante observar ainda que, na Tabela 3 , existem valores elevados na correlação entre as três dimensões da escala. Além de mostrar um problema na unicidade de cada subescala, este dado indica que alguma dimensão do amor pode estar se correlacionando com o FIT ou com a satisfação devido à correlação com as outras dimensões.

\section{Análise da Redução de Itens da ETAS}

No intuito de melhorar as propriedades psicométricas da ETAS, procedeu-se à redução de itens da mesma. Esta estratégia faz com que a escala perca um pouco na sua fidedignidade, mas acaba com o problema dos itens que saturam em mais de um fator. Com uma escala de 20 itens medindo os mesmos três fatores, Lemieux e Hale (1999, 2000) obtiveram coeficientes Alphas de Cronbach entre o,87 e 0,88, mas uma excelente estrutura fatorial. O grande problema de se ter uma escala diferente é o fato de que se estaria trabalhando com um instrumento diferente do restante dos estudos.

Por este motivo, é apresentada como sugestão uma versão reduzida da ETAS com 18 itens que, embora diferente da escala original, possui maior precisão para medir as três dimensões do amor. Trata-se de uma re-análise dos mesmos dados, na qual foram retirados itens dúbios ou que saturaram de maneira extremamente semelhante em itens mantidos nesta versão reduzida. A Tabela 4 mostra a análise fatorial da versão reduzida. O resultado do teste de esfericidade de Bartlett permaneceu significativo $\left(\chi^{2}\right.$ aprox. $=4542,250 ; g l=153 ; p<0,001)$ e o valor do teste 
Kaiser-Meyer-Olkin continuou indicando adequacidade amostral dos itens (0,936). Os valores dos Alpha de Cronbach permaneceram elevados, mesmo com a redução do número de itens de cada subescala para apenas seis $\left(a_{\text {intimidade }}=0,900 ; a_{\text {paixão }}=0,904 ; a_{\text {decisäo/compromisso }}=0,913 ; a_{\text {amor }}\right.$ $=0,941)$.

Tabela 4

Análise Fatorial da Versão Brasileira Reduzida da Escala Triangular do Amor de Sternberg (ETAS)

\begin{tabular}{|c|c|c|c|}
\hline & \multicolumn{3}{|c|}{ Fator } \\
\hline & Decisão/Compr. & Intimidade & Paixão \\
\hline $22(\mathrm{D} / \mathrm{C})$ - Espero que meu amor por ___ dure pelo resto da vida. & ,896 & & \\
\hline 32 (D/C) - Não deixaria nada atrapalhar meu compromisso com & ,883 & & \\
\hline 23 (D/C) - _ _ pode contar comigo quando tiver necessidade. &, 871 & & \\
\hline $02(\mathrm{D} / \mathrm{C})$ - Estou certo do meu amor por &, 781 & & \\
\hline $31(\mathrm{D} / \mathrm{C})$ - Estou determinado a manter minha relação com &, 756 & & \\
\hline $19(\mathrm{D} / \mathrm{C})$ - Tenho um compromisso com __, portanto & & & \\
\hline não permitirei que outras pessoas se ponham entre nós. &, 727 & & \\
\hline 11 (I) - Eu sinto que ___ realmente me entende. & & ,939 & \\
\hline 36 (I) - Eu sinto que eu realmente entendo & & ,828 & \\
\hline $10(\mathrm{I})-\mathrm{Eu}$ ativamente promovo o bem estar de & &, 801 & \\
\hline $14(\mathrm{I})$ - Eu recebo muito apoio emocional de & &, 756 & \\
\hline 39 (I) - Eu dou muito apoio emocional a & &, 752 & \\
\hline 21 (I) - Tenho uma relação afetuosa com __. & & ,656 & \\
\hline $15(\mathrm{P})-\mathrm{Eu}$ tenho fantasias com & & & ,926 \\
\hline $27(\mathrm{P})-\mathrm{Eu}$ gosto muito do contato físico com & & & ,921 \\
\hline $13(\mathrm{P})$ - Eu acho que ___ é pessoalmente muito atraente. & & & 877 \\
\hline 25 (P) - Quando eu assisto filmes românticos ou leio livros românticos, & & & \\
\hline eu penso em & & &, 752 \\
\hline $30(\mathrm{P})$ - Me pego pensando em ___ várias vezes durante o dia. & & &, 744 \\
\hline $20(\mathrm{P})$ - Meu relacionamento com ___ é muito romântico. & & ,302 &, 531 \\
\hline
\end{tabular}

Com relação às correlações entre as subescalas, esta versão reduzida encontrou valores semelhantes aos do primeiro estudo (vide Tabela 3). A dimensão da paixão obteve correlações (Pearson) moderadas com a intimidade $(r$ $=0,533, p<0,001)$ e com a decisão/compromisso $(r=$ $0,582, p<0,001)$. A correlação mais forte foi encontrada entre intimidade e decisão/compromisso $(r=0,714, p<$ $0,001)$. Apesar da versão reduzida da escala não ter eliminado estas correlações, pode-se dizer que os seis itens são representativos dos demais. Conforme pode ser observado na Tabela 2, as versões completa e reduzida da ETAS se correlacionam de maneira semelhante com os resultados do FIT. Os valores das correlações entre as dimensões originais e as da escala reduzida foram sempre superiores a $0,95(p<0,001)$.

\section{Discussão}

A versão traduzida para o português da ETAS mostrou ter uma boa estrutura fatorial e propriedades psicométricas adequadas. Apesar da presença de itens que saturaram em subescalas diferentes das propostas por Sternberg (1988), os três fatores propostos originalmente foram facilmente identificados, sugerindo indícios de validade de construto da Teoria Triangular do Amor com relação à amostra estudada.

Com certeza, a contribuição dos juízes avaliadores na adaptação do instrumento foi de fundamental importância para que a análise fatorial encontrasse resultados semelhantes ao da aplicação original. O fato de esta aplicação ter encontrado menos itens fora do fator pretendido que outros estudos (Chojnacki \& Walsh, 1990; Hernandez, 1999) pode ser atribuído ao papel destes juízes.

As comparações entre os índices de amor e a identificação real (i.e. Eu sou como meu parceiro) e ideal com o parceiro (i.e. Eu gostaria de ser como meu parceiro) e a semelhança parceiro real-parceiro ideal (i.e. Meu parceiro é do jeito que eu gostaria que ele fosse) mostraram correlações fracas e moderadas. O principal resultado aponta para uma correlação positiva entre a intimidade e a semelhança entre o parceiro real-ideal. Este resultado pode indicar que quanto mais próxima do ideal for a percepção real do parceiro, maior será a sensação de intimidade percebida no relacionamento. 
As comparações entre os escores de amor e os índices de satisfação no relacionamento mostraram correlações positivas elevadas com a intimidade e a decisão/compromisso e baixas com a paixão. Estes resultados sugerem que o sentimento de proximidade e conexão, juntamente com a sensação de que o relacionamento será mantido a longo prazo, estão diretamente ligadas à satisfação. Por outro lado, as dimensões satisfação com o relacionamento e atração física/sexual parecem estar menos relacionadas.

A análise fatorial foi feita no nível exploratório porque permite identificar as diferenças culturais da população para a qual o instrumento está sendo adaptado (Burnett \& Dart, 1997). Cabe salientar que os resultados encontrados no presente estudo são semelhantes aos descritos por Hernandez (1999) no Brasil, apesar do número reduzido de participante utilizados neste estudo. Os equivalentes dos itens 1, 16, 18, 28 e 29 também saturaram em um fator diferente do pretendido neste estudo. O equivalente do item 7 apresenta a mesma dualidade entre os fatores nos dois estudos. Apenas os itens 9 e 35 saturaram em um fator diferente neste estudo e foram para o fator esperado no estudo de Hernandez (1999). O contrário ocorreu com os equivalentes dos itens 5, 10, 12, 25, 34, 38 e 40. Os alphas de Cronbach encontrados foram extremamente satisfatórios, demonstrando a consistência interna da escala. Por outro lado, esta correlação entre os itens é algo que pode dificultar a identificação das dimensões na análise fatorial.

Cada versão da escala possui as suas peculiaridades, sendo que este estudo não elege nenhuma delas como a mais adequada para a sua utilização. Os resultados sugerem que ambas as versões da ETAS são psicometricamente adequadas para se mensurar o amor. O psicólogo ou pesquisador que necessitar fazer uso deste instrumento deverá levar em consideração que a versão completa da ETAS possui uma semelhança maior com o instrumento utilizado no exterior. Todavia, a versão reduzida possui melhor estrutura fatorial e, obviamente, é um instrumento de aplicação mais breve. Este estudo possui limitações com relação à especificidade da amostra, o que impede generalizações destes resultados. Os dados encontrados, porém, encorajam a realização de mais pesquisas no Brasil, a fim de identificar as peculiaridades do amor nos mais diversos tipos de relacionamento.

\section{Referências}

Aron, A., Fisher, H., Mashek, D. J., Strong, G., Li, H., \& Brown, L. L. (2005). Reward, motivation, and emotion systems associated with early-stage intense romantic love. Journal of Neurophysiology, 94, 327-337.

Aron, A., \& Westbay, L. (1996). Dimensions of the prototype of love. Journal of Personality and Social Psychology, 70, 535551

Bortz, J. (2005). Statistik für Human- und Sozialwissenschaftler. Berlin, Germany: Springer.
Burnett, P. C., \& Dart, B. C. (1997). Conventional versus confirmatory factor analysis: Methods for validating the structure of existing scales. Journal of Research and Development in Education, 30, 126-132.

Buss, D. M. (1989). Sex differences in human mate preferences: Evolutionary hypotheses tested in 37 cultures. Behavioral and Brain Sciences, 12, 1-49.

Chojnacki, J. T., \& Walsh, W. B (1990). Reliability and concurrent validity of the Sternberg Triangular Love Scale. Psychological Reports, 67, 219-224.

Engel, G., Olson, K. R., \& Patrick, C. (2002). The personality of love: Fundamental motives and traits related to components of love. Personality and Individual Differences, 32, 839-853.

Eysenck, H. J. (1970). The structure of human personality. London: Methven.

Freud, S. (1969). Os instintos e suas vicissitudes. In E. Salomão (Ed.), Edição eletrônica brasileira das obras psicológicas completas de Sigmund Freud: Vol. 14. Rio de Janeiro, RJ: Imago. (Original publicado em 1915)

Hendrick, C., \& Hendrick, S. S. (1989). Research on love: Does it measure up? Journal of Personality and Social Psychology, 56, 784-794.

Hernandez, J. A. E. (1999). Validação da estrutura da Escala Triangular do Amor: Análise fatorial confirmatória. Aletheia, 9, 15-25.

Hernández-Nieto, R. A. (2002). Contribuciones al análisis estadístico. Mérida, Venezuela: Universidad de Los Andes/ IESINFO.

Kelly, G. A. (1955). The psychology of personal constructs. New York: Norton.

Landis, J. R., \& Koch, G. G. (1977). The measurement of observer agreement for categorical data. Biometrics, 33, 159-174.

Lemieux, R., \& Hale, J. L. (1999). Intimacy, passion and commitment in young romantic relationships: Successfully measuring The Triangular Theory of Love. Psychological Reports, 85, 497-503.

Lemieux, R., \& Hale, J. L. (2000). Intimacy, passion and commitment among married individuals: further testing of the Triangular Theory of Love. Psychological Reports, 87, 941948.

Martson, P. J., Hecht, M. L., Manke, M. L., McDaniel, S., \& Reeder, H. (1998). The subjective experience of intimacy, passion, and commitment in heterosexual loving relationships. Personal Relationships, 5, 15-30.

Masuda, M. (2003). Meta-Analyses of love scales: Do various love scales measure the same psychological construct? Japanese Psychological Research, 45, 25-37.

Reis, B. F. dos (1992). O amor à luz da Psicologia científica. Psicologia: Reflexão \& Crítica, 5, 23-40.

Reis, B. F. dos (1995). Uma escala de atitudes frente a relações afetivas estáveis. Psicologia: Teoria e Pesquisa, 11, 67-71.

Reise, S. P., Waller, N. G., \& Comrey, A. L. (2000). Factor analysis and scale revision. Psychological Assessment, 12, 287-297.

Remschmidt, H., \& Mattejat, F. (1999). Der FamilienIdentifikations-Test (FIT). Manual. Göttingen, Germany: Hogrefe.

Rubin, Z. (1970). Measurement of romantic love. Journal of Personality and Social Psychology, 16, 265-273.

Schoepflin, M. (2004). O amor segundo os filósofos. Bauru, SP: Edusc. 
Serrano Martinez, G., \& Carreño Fernandez, M. (1993). La teoria de Sternberg sobre el amor. Analisis empirico. Psicothema, 5(Suppl.), 151-167.

Skinner, B. F. (1991). Questões recentes na análise comportamental. Campinas, SP: Papirus.

Stephenson, W. (1953) The study of behavior. Q-technique and its methodology. Chicago: University of Chicago Press.

Sternberg, R. J. (1986). A triangular theory of love. Psychological Review, 93, 119-135.

Sternberg, R. J. (1988). The triangle of love. New York: Basic Books.

Sternberg, R. J. (1997). Construct validation of a triangular love scale. European Journal of Psychology, 27, 313-335.

Sternberg, R. J. (1998). Love is a story: A new theory of relationships. New York: Oxford.

Sternberg, R. J., \& Grajek, S. (1984). The nature of love. Journal of Personality and Social Psychology, 47, 312-329.

Teodoro, M. L. M. (2000). Habilidades sociais e processos de identificação em crianças e adolescentes. Disser tação de Mestrado nãopublicada, Departamento de Psicologia da Faculdade de Filosofia e Ciências Humanas, Universidade Federal de Minas Gerais, Belo Horizonte, MG.

Teodoro, M. L. M. (2005). Kognitive Repräsentationen familiärer Beziehungen. Methodenkritische Untersuchungen zu Kohäsion und Hierarchie innerhalb dês familiären Systems. Hamburg, Germany: Kovacs.

Yela, C. (1996). Componentes básicos del amor: algunas matizaciones al modelo de Sternberg. Revista de Psicología Social, 11, 185-201.

Zwick, W. R., \& Velicer, W. F. (1986). Comparison of five rules for determining the number of components to retain. Psychological Bulletin, 99, 432-442. 